\title{
从技术经济视角初探 LNG 接收站改扩建项目管理中的采购应用
}

\author{
A Preliminary Study on the Management of LNG Receiving Station Reconstruction and
} Extension Project from the Perspective of Technology Economy 谭秋月

Qiuyue Tan

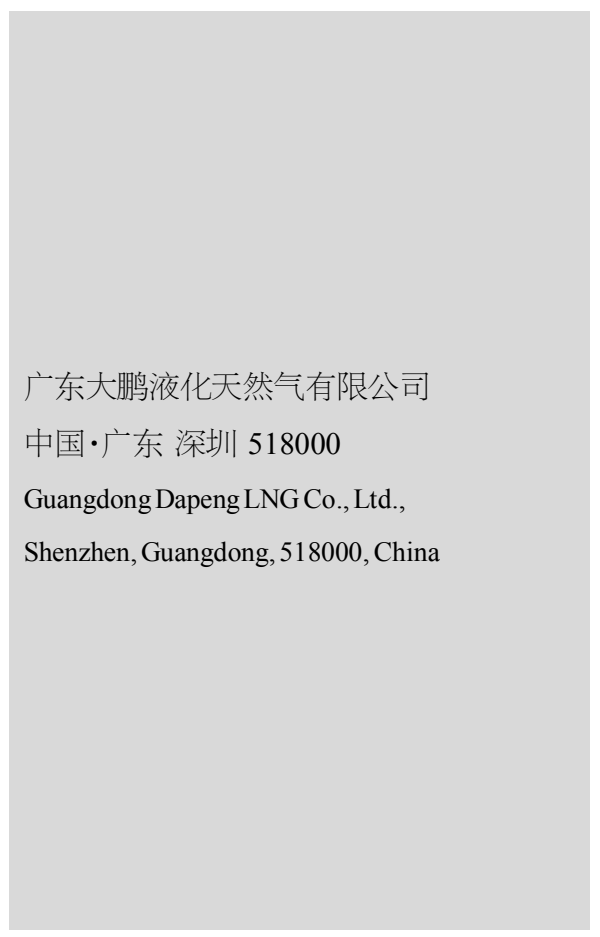

【摘 要】广东 LNG 试点项目一期总投资 300 多亿元人民币, 项目包括 LNG 站线项目、4 个新建电厂、1 个油改气电厂、4 个城市燃气管网、 LNG 造船及运输。自从一期工程投产以 来, 为保障安全供应, 接收站根据现场情况, 实施了一系列改扩建工程, 从国际承包商主导 的总包模式转化为业主自主管理的设计采购施工管理, 摸索出一条适合 LNG 接收站改扩 建项目的项目管理模式, 论文针对项目管理中的采购应用, 结合多年实践经验, 总结提炼, 从技术经济视角探索 LNG 接收站改扩建项目采购管理的相关内容。

【Abstract】The first phase of the pilot project in Guangdong LNG has a total investment of more than 30 billion yuan. The projects include LNG station line projects, four new power plants, one oil-to-gas power plant, four urban gas networks, LNG shipbuilding and transportation. Since the first phase of the project was put into operation, in order to ensure the safe supply, the receiving station has carried out a series of reconstruction and extension projects according to the site conditions, from the international contractor-led general package mode to the owner-owned design procurement construction management, and found out a project management model suitable for the LNG receiving station reconstruction and extension project.

【关键词】技术经济; 项目管理; 采购应用

【Keywords】technical economy; project management; procurement application 【DOI】10.36012/emr.v2i1.1058

\section{1 引言}

技术经济学顾名思义就是研究技术和经济间的关系的科 学。在工程的决策阶段、设计阶段、施工阶段,都需要从建筑技 术学科和经济学科两个方面来分析和研究, 才能更好地提升 建设项目的效益。LNG 改扩建项目同样如此,因此,笔者分阶 段来探讨该问题。而建设项目的采购管理,是最能直接体现技 术经济的出口。与一般的供应链采购管理不同,建设项目的采 购管理涉及建筑技术学科的各个阶段。为了满足采购对 LNG 接收站项目高可靠性高技术要求的特点, 同时兼顾经济性, 笔 者选择从技术经济对采购管理的影响着手，从技术经济视角 讨论对 LNG 接收站改扩建项目采购管理。

\section{2 项目前期研究对采购管理技术经济性} 的指引

一般而言, 大的改扩建项目的前期研究阶段包括可行性
研究、投资决策等。有资料表明, 在建设工程项目成本控制中, 施工阶段只能控制投资的 $20 \%$ 左右, 而在建设工程项目决策 和设计阶段,控制投资的可能性在 60\% 80\%。因此项目前期 研究形成的策略对后期采购管理有指引甚至决定性的作用, 如果策略出现偏离, 后期的采购管理会变得比较被动。而较小 的改扩建项目的前期决策同样对项目执行阶段的采购起指引 甚至决定性作用, 只是阶段性没有大型改扩建项目明显, 但小 项目对项目整体的管控同样有效。

\section{3 项目设计阶段对采购管理技术经济性} 的作用

设计阶段是改扩建项目的重要阶段, 如果能有效运用技 术经济分析进行成本优化, 能够成为决定项目经济性的关键 阶段。如由于设计人员对材料的认识不足或其他原因导致有 些设计的安全系数大大超过了设计规范要求, 由此肯定会造 成工程投资的增加和浪费。该过程对采购的规格数量等关键 
参数起直接决定作用。在这一过程中必须重视以下几点:

(1)改扩建项目的设计服务, 应全面采用招投标竞争机制, 做到技术与经济互相统一和协调。同时,由于改扩建项目的特 殊性, 如果项目涉及接收站工艺及前期项目衔接较多, 应兼顾 考虑设计院对现场熟悉程度和对 LNG 接收站的设计能力。因 为, 项目始终是追求进度的, 在进度的要求下, 设计的及时性 和准确性直接决定了采购的效率。

(2)确定设计承包商后, 对现场踏堪和现场代表的工作要 做足, 避免出现设计与现场脱节的现象。通常, 对大型改扩建 项目,一般要求现场代表驻场。对小型改扩建项目, 出于经济 性考虑, 设计院出席重要会议和现场踏勘, 不派驻现场代表, 控制项目管理成本。现场代表对现场的熟悉, 有利于更准确的 设计,避免设计偏差带来采购错误。

(3)技术与经济相分离是中国工程项目成本管理水平落 后、工程项目超支现象严重的主要原因。从这个角度, 工程造 价其实不是由造价人员决定的, 从实践上看, 设计人员是管理 项目经济性的主角。设计图纸和设计方案直接决定工程造价。 设计的材料规格、数量, 均是从图纸上通过软件导出, 是采购 的直接依据。同时, 还要求设计院负责采购询价书的出具, 作 为采购的主要依据。可见, 设计与经济直接相关、直接相连、不 可分割, 是项目管理的龙头, 也是采购的龙头。

(4)加强变更管理,减少设计变更。对非发生不可的设计变 更, 应尽量提早实现。变更发生的越早损失就越小, 反之损失 就越大。为此, 应建立相应的设计管理制度, 尽可能把设计变 更控制在设计阶段。一旦形成采购文件、开始招标、开始长 周期设备的采购工作, 再来修改设计参数, 将会导致整个采购 陷入被动状态, 有可能造成合同违约甚至巨大的经济损失。导 致整个项目无法完成预期目标。从这个角度来看, 设计对采购 的直接作用可谓巨大, 对整个项目的直接作用也显而易见。

LNG 接收站改扩建项目具有高技术性、高可靠性特点, 对以上设计的要求必须更加严格, 特别是对接口和与原接 收站界面设计, 须严格审核设计图纸, 以避免造成后期采购 损失。

\section{4 项目施工阶段对采购管理技术经济性}

\section{的作用}

工程的实施阶段即施工阶段, 是建设工程项目价值和使 用价值实现的最重要阶段。施工阶段管理投资控制应加强对 施工现场的管理, 推行按图施工, 制约材料用量, 合理确定材 料价格, 严格对待现场签证, 严格控制设计变更, 进行工期成 本的优化选择。对 LNG 改扩建项目而言, 同样如此, 其技术经 济性采购应用重点分析如下:
(1)改扩建项目的施工开始后, 往往理想的设计准确性状 态被打破, 随着施工的进行, 设计会同步进行修改优化, 在这 个过程中, 理想的状态是设计的优化不会对前期已经采购的 材料产生影响, 因为后期采购的材料可以随着设计的调整而 调整。因此, 采购需要紧跟设计的步伐, 一但出现设计调整, 可 能会影响前期已经采购的材料, 做好最坏的打算, 做好最充分 的准备。一旦涉及公司内部采办财务政策, 可进行沟通协调。若 涉及外部合同违约招投标事项, 需要项目经理及时做出决策。

(2)合理编制、优化、调整施工进度计划。这样就可以有条 不紊地协调现场施工, 缩短工期, 既降低了人工费用和管理费 用, 又加快了资金、设备和材料的周转速度。施工进度的及时 调整也为采购可能进行的调整预留了足够的空间, 使整个项 目计划具有弹性, 做到不影响关键路径, 游刀有余。

(3)加强对工程量和材料量的控制。严格按照设计图纸施 工, 控制工程量。加强材料、设备采购管理, 要对工程材料的采 购、运输、收发、保管等环节进行合理控制, 在采购环节建立监 督机制[1]。

\section{5 工程竣工结算阶段对采购管理技术经 济性的作用}

工程竣工结算是建设工程项目投资控制的最后一个环 节, 应把好结算审查关, 严格审核工程量、审核项目单价、审核 取费程序的准确性, 核减未按合同条款履行的违约费用。在采 购实践中, 特殊采购材料如消防类材料的结算有时会要求与 专项竣工验收相挂钩, 以避免竣工验收出现问题无供应商解 决的情况。

在建设项目中科学合理地应用技术经济分析, 不仅可以 促进项目整体目标的实现, 而且为建设项目创造了更高的经 济效益和社会效益。笔者基于在 LNG 接收站改扩建项目的实 践经验, 结合技术经济理论, 从项目管理及其采购管理的角 度, 分析总结了在项目管理不同阶段, 各种改扩建项目面对技 术经济性的技术选择和经济选择, 对最终采购管理形成实践 经验。

\section{6 结语}

总的来说, $\mathrm{LNG}$ 接收站安全性和耐久性要求在采购实践 中不能盲目追求最低价, 也不能盲目追求技术性而忽略经济 性, 而是考虑如何结合具体阶段、具体项目、具体技术特点, 运 用技术经济理论解决采购中的各种综合性问题, 而非单纯的 采购问题。

\section{参考文献}

[1]潘艳珠.工程技术经济[M].北京:机械工业出版社,2010. 